\title{
BIOMIMETIC PHOTODIODE DEVICE WITH LARGE PHOTOCURRENT RESPONSE USING PHOTOSYNTHETIC PIGMENT-PROTEIN COMPLEXES
}

\author{
Damar Yoga Kusuma ${ }^{*}$, Hariyadi Soetedjo ${ }^{1,2}$ \\ ${ }^{1}$ Department of Physics, Faculty of Science, Universitas Ahmad Dahlan \\ Jl. Prof. Dr. Soepomo, Janturan, Umbulharjo, Yogyakarta 55164 \\ ${ }^{2}$ Center for Integrated Research and Innovation, Universitas Ahmad Dahlan (CIRNOV-UAD) \\ Jl. Cendana 9A, Semaki, Umbulharjo, Yogyakarta 55166
}

Recieved: O8 $^{\text {th }}$ February 2017; Revised: $20^{\text {th }}$ April 2017; Accepted: $21^{\text {th }}$ April 2017

\begin{abstract}
Efficient light to energy conversion was demonstrated in solid-state, lateral photodiodes device containing photosynthetic light harvesting chlorophyll protein complexes as active materials. The device exhibits the highest reported photocurrent density response of $365 \mu \mathrm{A} / \mathrm{cm}^{2}$ when illuminated at $320 \mathrm{~mW} / \mathrm{cm}^{2}$ radiation source power. The photocurrent response was stabled over $10^{4} \mathrm{~s}$ of continuous cycles of dark and illumination states. The short rise and decay time of the photocurrent waveform within sub-second range indicates an effective photogeneration and charge extraction within the device. Optical bandgap extraction using absorbtion coefficient method reveals that the energy gap of the active materials ranges from 2.8 to $3.8 \mathrm{eV}$, correspond to the Photosystem I and Photosystem II of the photosynthetic pigmen-protein complexes.
\end{abstract}

Keywords: Photocurrent; Photodiode; Photosynthesis; Chlorophyll; PSI; PSII

\section{Introduction}

Efficient light-to-energy conversion in photosynthesis has inspired the quest for an efficient, clean and renewable energy source of the future. In the heart of photosynthetic process, the reaction centers (RCs) facilitates photo-induced charge separation with a quantum yield near unity. ${ }^{1}$ The highly efficient process relies on the seamless organization of light-harvesting pigments, protein complexes and molecular functional groups held in precise geometries, wherein the molecular electronic states are intricately arranged to enable the unidirectional flow of charges.

Early work on bioinspired optoelectronics system employed photosynthetic pigment as active materials in metal-chlorophyll-metal devices. ${ }^{2-4}$ However, the device showed rather unsatisfactory performance with efficiency below $0.5 \%$. The absence of charge acceptor moieties within the active layer was caused this low performance. The subsequent improvement on device performance was realized when n-type or $\mathrm{p}$ type semiconductor material ${ }^{5-6}$ was introduced along with chlorophyll. A modest power conversion efficiency of $2.3 \%$ is achieved when chlorophyll mixed with C70. ${ }^{6}$ In all of these studies the researcher failed to perceive photosynthesis as a whole interconnected system, which resulted in a modest efficiency of the system. In the natural setting of photosynthesis, light is absorbed by the antenna complex of Photosystem II (PSII) to be funneled to the photosynthesis reaction center P680. PSII antenna consists of protein-embedded chlorophyll to absorb light and carotenoids to quench excess radiation energy. The funneled energy excites the electron of P680 into an excited $\mathrm{P} 680^{*}$ state. The process is quickly followed by electron transfer from P680* (formed P680+) to the primary electron acceptor pheophytin, quinone 
molecules $\mathrm{Q}_{\mathrm{A}}-\mathrm{Q}_{\mathrm{B}}$, and plastoquinone to cytochrome b6f protein complex. Subsequently the charge is transferred by phthalocyanine to $\mathrm{P} 700$ reaction center of Photosystem I (PSI) and then ferredoxin for ATP generation. The redox process is completed when P680+ regains electron from splitting of water molecules into oxygen and protons. ${ }^{1}$

Most recently, the biomimetic strategy has been borrowed from photosynthetic organisms utilizing the whole photosynthetic pigments and proteins to be incorporated into the man-made photocurrent devices. ${ }^{7-13}$ Thereby, the high efficiency of the photosynthesis might be retained in the artificial devices. Bilayer structure of recombinant ferredoxin and chlorophyll shows one directional transport of electron from chlorophyll to ferredoxin molecule during visible light exposure. ${ }^{7}$ Similarly, at the time photosynthetic carotenoids introduced to the bulk hetero-junction solar cell, it helps to quench the excessive radiation detrimental to photocurrent generation. ${ }^{8}$ Recently, by employing bacterial photosynthesis reaction center (RC)-light harvesting core complex (LH 1) immobilized onto the Gold electrode, a relatively high photocurrent density of 7.1 $\mu \mathrm{A} / \mathrm{cm}^{2}$ had been achieved in a bio-photoelectro-chemical cell structure. ${ }^{9}$ An improvement in photocurrent density up to $10 \mu \mathrm{A} / \mathrm{cm}^{2}$ was obtained when the protein was suspended into the supported lipid bilayer. ${ }^{10}$ The highest photocurrent density response of $45 \mu \mathrm{A} / \mathrm{cm}^{2}$ is obtained when the protein complex was densely packed via Langmuir film deposition. ${ }^{11}$ Most of these works were conducted in bio-photo-electrochemical cells which required electrolyte solution and must be confined and sealed. Up to now, only one work reported the solidstate bio-photovoltaic device albeit the inferior device performance. ${ }^{12}$

Herein, we demonstrated a solid state biomimetic photodiode device with large photocurrent responses. The active material was attained from the Alfalfa leaves extract which retained the photosynthetic pigments and proteins complexes. Large photocurrent density response of $188 \mu \mathrm{A} / \mathrm{cm}^{2}$ was achieved under $320 \mu \mathrm{W} / \mathrm{cm}^{2}$ fluorescent radiation power. The devices showed stable photocurrent responses without significant reduction in performance under continuous cycling test for $10^{4}$ seconds.

\section{Methods}

Extract of Alfalfa (Medicago sativa l.) leaves was obtained from K-Link K-Liquid Chlorophyll containing 4\% leaves extract in aqueous solution. The leaves extract retained its photosynthetic pigments and proteins complexes including the PSI, PSII and cytochrome b6f. The used leaves extract was without further purification. A lateral metalorganic-metal photodiode device was obtained by spin coating or drops-casting of the leaves extract solution onto patterned $\mathrm{Cu}$ electrode. The equivalent electrode length was $32 \mathrm{~mm}$ while the electrode gap was 0.05 $\mathrm{mm}$. The leaves extract was drop-casted onto the gap and allowed to dry at room temperature and ambient condition. The drop-casted film of leaves extracts was also prepared on a glass substrate with exact amount for spectrophotometric studies. Prior to leaves extract deposition, the substrates were rinsed with ethanol and deionized water and dried at room temperature.

The optical properties, including transmittance, absorbance, and optical bandgap of the pigment-protein complexes were recorded by using Hitachi U-2900 Spectrophotometer on UV and visible wavelengths from 190-950 nm. Optical bandgap extraction was performed on the aqueous solution pigment-protein complexes sample at various concentration whereas other data were obtained from the thin-film samples. Photocurrent response measurements were performed by manually exposing and covering the device to a 40 Watt fluorescent lamp. Voltage and current response were recorded by using PC Link Digital Multimeter VA18B. To evaluate the photocurrent response, the resistance across the device was measured against time during the dark and illumination states at various 
light intensities. Cycling endurance test of the photodiode was performed by monitoring the photocurrent response as the device subjected to continuous cycles of dark and illumination.

\section{Result and Discussion}

Figure 1 shows the absorbance spectra of the leaves extract in the solution and film forms. The large absorbance peak around 214 $\mathrm{nm}$ corresponds to the absorbance by the antenna complexes of PSI and PSII. ${ }^{13-14}$ It shows that most of the PSI and PSII protein complexes are still intact within the leaves extract. The absorbance peak around $400 \mathrm{~nm}$ and the red maxima at $661 \mathrm{~nm}$ signify the presence of molecular chlorophyll. ${ }^{15}$ The leaves extract also contains several carotenoids mainly $\beta$-carotene, lutein, neoxanthin and violaxantin. ${ }^{15}$ The large discrepancies between the blue absorption and red absorption of chlorophyll suggest that the carotenoid presents at much higher amount compared to unbound chlorophyll molecules. The Large absorption peak of PSI and PSII also suggest that most of the chlorophyll molecules are bounded to the protein complexes.

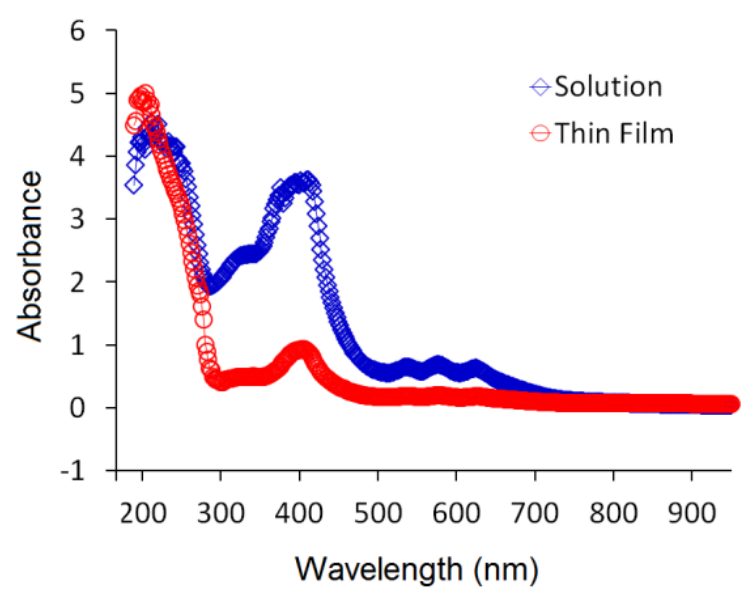

Figure 1. The absorbance spectrum of Alfalfa leaves extract containing the light harvesting chlorophyll-protein complexes in the aqueous solution and thin film forms

Note that the similarity of the absorbance spectra of the solution and the film form indicates that the leaves extract deposition process do not alter much on the structure and composition of the photosynthetic protein complexes PSI and PSII. The $214 \mathrm{~nm}$ peak retains its high absorbance whereas the reduction of $400 \mathrm{~nm}$ peak shows that the carotenoids contents decrease in the film forms. As the thickness of the film increases, the absorbance increases accordingly and thus generates higher photocurrent response when illuminated. However, increasing the film thickness also causes an increase in the dark current level, which is unfavorable. Taking into consideration the trade-off between photocurrent and dark current level, an optimized film thickness of $1.5 \mu \mathrm{m}$ is employed for subsequent studies.

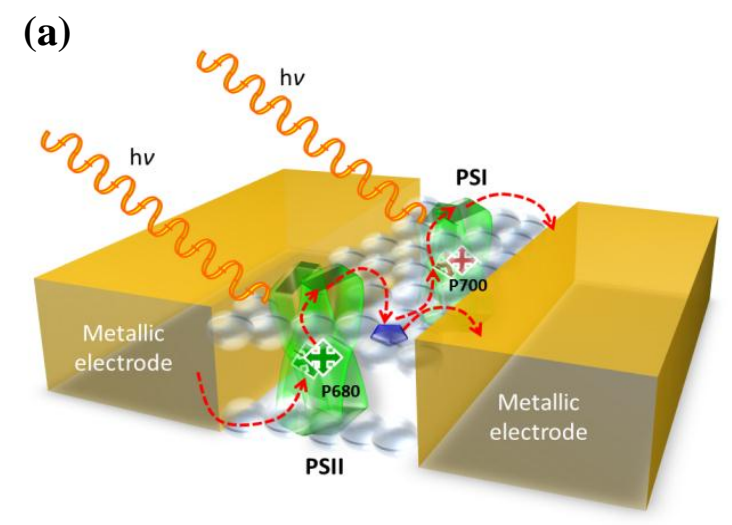

(b)

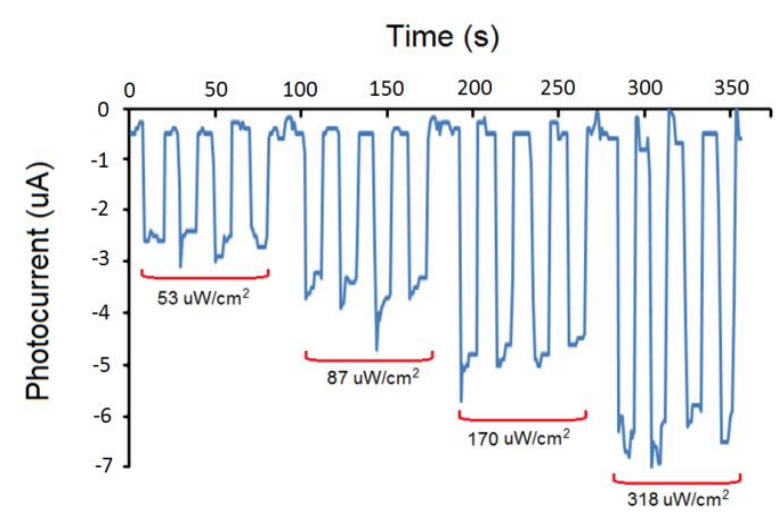

Figure 2. (a) Schematic structure of the lateral photodiode devices. The active material of light harvesting chlorophyllprotein complexes are deposited into the narrow electrodes gap (b) The photocurrent response of the device measured under polychromatic fluorescence lamp at various intensities 
Figure 2(a) depicts the biomimetic photocurrent process employed in this work. Light radiation is absorbed by the antenna complex of PSI and PSII. The absorbed energy is used to excite electrons from reaction centers P680 and P700. Further, the electrons follow the charge transfer path through several proteins and transport molecules to be collected in the anode. To complete the redox process, electrons are injected from the cathode to reduce the $\mathrm{P} 680+$ and P700+ to its original state. Figure 2(b) shows the photocurrent response of the device during dark and illuminated state. The device was initially in dark state and then exposed fluorescence illumination for $10 \mathrm{~s}$. Subsequently, the device was put in dark state for $10 \mathrm{~s}$ to allow for relaxation. The dark-illumination cycles were repeated several times to obtain a representative reading. The photocurrent response is observed to increase linearly with light intensities. A $50 \mathrm{~mW} / \mathrm{cm}^{2}$ light intensity generates photocurrent density response of $162 \mu \mathrm{A} / \mathrm{cm}^{2}$. Increasing the light intensities to 90 and $170 \mathrm{~mW} / \mathrm{cm}^{2}$ resulted in an increase of photocurrent density level to 206 and $300 \mu \mathrm{A} / \mathrm{cm}^{2}$ respectively. Large photocurrent density response of $365 \mu \mathrm{A} / \mathrm{cm}^{2}$ is achieved when $320 \mathrm{~mW} / \mathrm{cm}^{2}$ light intensity is used.

The photocurrent response exhibits a sharp, square-shaped waveform with very short rise time and decay time in the subsecond range as shown in Figure 3(a). It indicates an efficient charge transfer between the protein complexes and the electrodes where most of the photo-generated electrons are extracted from the electrode. ${ }^{16}$ These results show superior performance compared to the previously reported work on similar systems where the waveform showed a nonsaturating profile with long rise and decay times in the order of minutes. ${ }^{9-11}$ To evaluate the endurance of the photocurrent response, cycling stability test was performed by monitoring the photocurrent response as the device continuously cycled between dark and illuminated states. For cycling test, the light intensity was fixed at $320 \mathrm{~mW} / \mathrm{cm}^{2}$. The cycling endurance test result is shown in Figure 3(b). Both the dark current and photocurrent responses show relatively stable reading over the cycling test period of $10^{4} \mathrm{~s}$. This finding revealed that the pigmentprotein complexes obtained from the Alfalfa leave extract are photo-active.

(a)

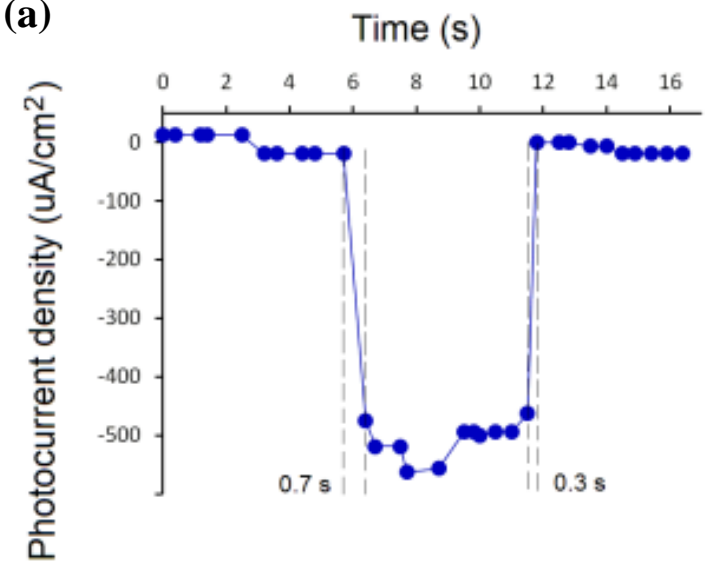

(b)

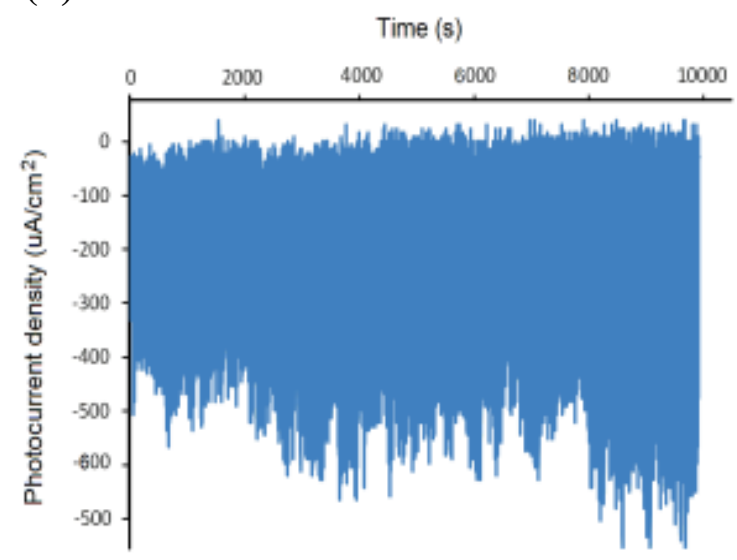

Figure 3. (a) Enlarged view of the photocurrent switching signal reveals rapid rise time and decay time dynamics of the active material (b) Photocurrent response of the device under continuous cycling test for $10^{4} \mathrm{~s}$. The light intensities were fixed at 320 $\mathrm{mW} / \mathrm{cm}^{2}$.

Optical band-gap of the active material is extracted from the intercept of the graph to the photon energy axis in $(\alpha h v)^{2}$ against the photon energy (hv) plot as shown in Figure 4. For the film sample, there are two major energy-gap observed within the $2.8 \mathrm{eV}$ and $3.8 \mathrm{eV}$ bands. These observed band-gap 
values correspond to the blue absorption of PSI, PSII, and Light Harvesting Antenna Complexes (Lhc) of photosynthetic protein complexes as reported in the literature. ${ }^{17-18}$ The result shows that the active material retains its photo-activity even in the solidstate thin film forms.

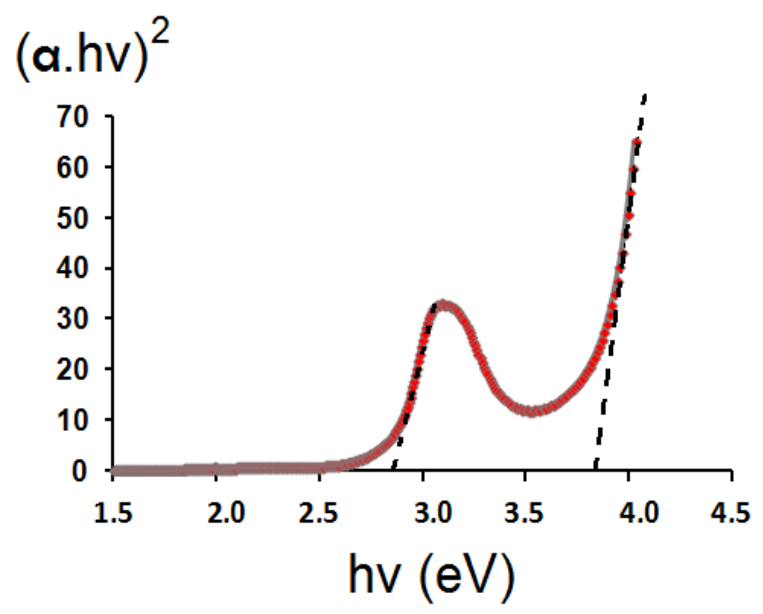

Figure 4. Optical absorption curves of pigment-protein complexes from Alfalfa leaves extract at various film thickness.

There were at least three factors that make this work distinct from the previously reported works. In this work, complete set of photosynthesis chlorophyll-protein complexes including its transport molecules was employed instead of individual component. In addition, our device is in a solid-state form in which the absence of liquid electrolyte eliminates the unnecessary capacitive double layer effect commonly encountered in the electrochemical device structure. ${ }^{19}$ Lastly, the lateral structure of the device prevents degradation of the active organic layer as it eliminates the needs to deposit the top electrode above the active materials.

\section{Conclusion}

To conclude, a large photocurrent response from light-harvesting chlorophyllprotein complexes thin film devices has been demonstrated. The device exhibits large photocurrent density response of $365 \mathrm{uA} / \mathrm{cm}^{2}$ which has the highest among reported results based on solid state devices. The sharp, square-shaped photocurrent waveform with short rise and decay time indicates that the photogeneration and charge extraction occur in an effective manner. The photocurrent response shows excellent cycling stability when cycled continuously under dark and illumination states up to $10^{4} \mathrm{~s}$. These findings envision greater accommodation of bioinspired bio-photo-electro-chemical concepts towards high-performance solar energy harnessing, solar fuel generation, and other optoelectronic devices applications.

\section{Acknowledgment}

This work has been supported by Lembaga Penelitian dan Pengembangan, Universitas Ahmad Dahlan research grant with contract number PDP-158/LPPUAD/III/2016.

\section{References}

1. Blankenship RE. Molecular Mechanisms of Photosynthesis. Hoboken, NJ: Blackwell Science;2002.

2. Tang CW, Albrecht AC. Photovoltaic effects of metal-chlorophyll-a-metal sandwich cells. J. Chem. Phys. 1975; 63(2):2139-2142.

3. Segui J, Hotchandani S, Baddou D, Leblanc RM. Photoelectric properties of ITO/ cadmium sulfide/ chlorophyll a/ silver heterojunction solar cells, J. Phys. Chem. 1991; 95(22):8807-8812.

4. Farag AAM. Electrical and photovoltaic characteristics of sodium copper chlorophyllin /n-type silicon heterojunctions. Appl. Surface Sci. 2009; 255(9):4938-4943

5. Yun JJ, Jung HS, Kim SH, Han EM. Chlorophyll-layer-inserted poly(3-hexylthiophene) solar cell having a high lightto-current conversion efficiency up to 1.48\%. Appl. Phys. Lett. 2005;87(12): 123102

6. Wang YW, Sasaki S, Zhuang T, Tamiaki $\mathrm{H}$, Zhang JP, Ikeuchi T, Hong Z, Kido J, Wang XF. Dicyano-functionalized chlorophyll derivatives with ambipolar 
characteristic for organic photovoltaics, Org. Electron. 2013; 14(8):1972-1979

7. Choi JW, Lee DB, Oh BK, Min J, Kim KS. Molecular Scale Photodiode of Recombinant Ferredoxin/Chlorophyll a Heterostructure. J. Nanoscience and Nanotechnology. 2008; 8(9):4527-4532

8. Wang XF, Wang L, Wang Z, Wang Y, Tamai N, Hong Z, Kido J. Natural Photosythetic Carotenoids for SolutionProcessed organic Bulk-Heterojunction Solar Cells. J. Phys. Chem. C. 2013; 117(2):804-811

9. Yaghoubi H, Lafalce E, Jun D, Jiang X, Beatty JT, Takshi A. Large Photocurrent Response and External Quantum Efficiency in Biophotoelectrochemical Cells Incorporating Reaction Centers Plus Light Harvesting Complexes, Biomacromol. 2015; 16(4):1112-1118

10. Gebert J, Reiner-Rozman C, Steininger C, Nedelkovski V, Nowak C, Wraight, CA, Naumann RLC. Electron Transfer to Light-Activated Photosynthetic Reaction Centers from Rhodobacter sphaeroides Reconstituted in a Biomimetic Membrane System. J. Phys. Chem. C 2015; 119(2):890-895

11. Kamran M, Delgado JD, Friebe V, Aartsma TJ, Frese RN. Photosynthetic Protein Complexes as Bio-photovoltaic Building Block retaining a High Internal Quantum Efficiency, Biomacromol. 2014; 15(8):2833-2838

12. Gordiichuk PI, Wetzelaer GJAH, Rimmerman D, Gruszka A, de Vries, JW, Saller M, Gautier DA, Catarci S, Pesce D, Richter S, Blom PWM, Herrmann A. Solid-State Biophotovoltaic Cells Containing Photosystem I. Adv. Mater. 2014; 26(28):4863-4869

13. Zolla L, Rinalducci S, Timperio A, Huber CG. Proteomics of LightHarvesting Proteins in Different Plant Species. Analysis and Comparison by Liquid Chromatography-Electrospray Ionization Mass Spectrometry, Photosystem I. Plant Physiol. 2002; 130(4):1938-1950
14. Zolla L, Timperio AM, Walcher W, Huber CG. Proteomics of LightHarvesting Proteins in Different Plant Species. Analysis and Comparison by Liquid Chromatography-Electrospray Ionization Mass Spectrometry, Photosystem II, Plant Physiol. 2003; 131(1):198-214

15. Lichtenthaler HK, Buschmann C. Chlorophylls and Carotenoids: Measurement and Characterization by UV-VIS Spectroscopy. Current Protocols in Food Analytical Chemistry. 2001; F:F4, F431-F438

16. Mukherjee B, Mukherjee M, Choi Y, Pyo S. Organic Phototransistor with ntype Semiconductor Channel and Polymeric Gate Dielectric. J. Phys. Chem. C 2009; 113(43):18870-18873

17. Santabarbara S, Heathcote P, Evans MC. Modelling of the Electron Transfer Reaction in Photosystem I by Electron Tunneling Theory. Biochim Biophys Acta $2005 \mathrm{Jul} ; 1708(3): 283-310$

18. Shi LX, Hall M, Funk C, Schroder WP. Photosystem II, a Growing Complex: Updates on Newly Discovered Components and Low Molecular Mass Proteins. Biochim Biophys Acta 2012 Jan; 1817(1):13-25

19. Gratzel M. Photoelectrochemical Cells. Nature 2001 Nov; 414:338-344 